\title{
Lung function and short-term outcome in young asthmatic children
}

\author{
B. Klug, H. Bisgaard
}

Lung function and short-term outcome in young asthmatic children. B. Klug, H. Bisgaard. (C) ERS Journals Ltd 1999.

ABSTRACT: The aims of this study were to investigate lung function in 2-5-yr-old stable asthmatic children consecutively referred from general practitioners and to analyse the outcome on the basis of their requirement for antiasthmatic treatment and symptoms after 1.6-4.5 yrs.

Lung function was measured in 110 children with a mean \pm SD age of $3.8 \pm 1.0$ yrs using the interruptor technique (resistance assessed using the interruptor technique (Rint)), whole body plethysmography (specific airway resistance ( $R$ aw) and respiratory resistance $(R r s, 5)$ and reactance at $5 \mathrm{~Hz}(X \mathrm{rs}, 5)$ using the impulse oscillation technique.

$R$ int, $s R$ aw, $X$ rs, 5 and $R$ rs, 5 were suggestive of impaired lung function in $44 \%, 14 \%$, $11 \%$ and $7.5 \%$ of the children, respectively, with a predominance of children aged $2-3$ yrs. Sixty-five per cent were treated with inhaled steroids, and $35 \%$ were treated only with $\beta_{2}$-agonists as needed; lung function was not significantly different between these two groups. Outcome after $2.9 \pm 0.7$ yrs was not significantly different between children with $R$ int measurements above and those children with $R$ int measurements within the reference range at enrolment. Of these children, 58 and $59 \%$ were currently on antiasthmatic treatment, and $40 \%$ and $49 \%$ had current symptoms, respectively.

Impairment of lung function may be a common finding in stable young asthmatic children, but apparently this is not a risk factor for persistence of asthmatic symptoms.

Eur Respir J 1999; 14: 1185-1189.
Dept. Pediatrics 5003, National University Hospital, Rigshospitalet, DK-2100 Copenhagen, Denmark

Correspondence: B. Klug, Dept. Pediatrics 5003, National University Hospital, Rigshospitalet, DK-2100 Copenhagen, Denmark Fax: 4535456713

\section{Keywords: Asthma}

asthma therapy

cross-sectional studies

preschool children

prognosis

respiratory function tests

Received: November 241998

Accepted after revision November 71998

This study was supported by grants from Danish Ministry of Health and Astra Draco, Sweden.
The diagnosis and monitoring of airway diseases involving wheeze in young children relies mainly on the history provided by the parents of the children and clinical observations. Reliable data on lung function can rarely be obtained in this age group using standard lung function tests [1]. A number of techniques applicable to lung function measurement in young children have recently been evaluated [2-4]. These techniques require passive cooperation only and measurements can be performed in unsedated young children down to the age of 2 yrs.

The aim of the present study was to provide data on lung function in a sample of young asthmatic children, 2-5 yrs of age, consecutively referred from general practitioners. Subsequently, the clinical outcome in these children after 3 yrs was assessed in order to investigate the prognostic value of the lung function measurements.

\section{Methods}

\section{Patients}

Asthmatic children aged 2-5 yrs referred to the paediatric asthma outpatient clinic from local general practitioners in the inner city of Copenhagen, Denmark were eligible for the study. The children were consecutively enrolled in the study over a period of 2 yrs. All children provided a history of three or more episodes of wheezing after the age of 1 yr. Children who had other concurrent chronic lung disease were not included in the study nor were children who were referred from other hospitals. Whether or not the child had a history of eczema and the parents had a history of asthma or hay fever requiring medical treatment was recorded. The children were considered to be asymptomatic if they had no wheeze or rhonchi on auscultation and had been without symptoms of wheeze in the preceding 2 weeks. Treatment with $\beta_{2}$ agonists was stopped $6 \mathrm{hrs}$ prior to the examination.

The parents were interviewed by telephone concerning their child's medical treatment and symptoms during the past year $1.5 \mathrm{yrs}$ after enrolment of the last patient. During this interview a questionnaire was filled in to determine whether or not the child was currently being treated with an inhaled steroid or a $\beta_{2}$-agonist alone or whether treatment had been stopped. In children who had been taken off inhaled steroids, the duration of time since withdrawal of treatment was recorded. The parents were asked to estimate the number of episodes of cough with wheeze lasting $>2$ days in their child during the past year. The study was approved by the local ethics committee and written informed consent was obtained from the parents.

\section{Measurements of lung function}

Lung function measurements were obtained using three techniques: the interruptor technique (resistance assessed using the interruptor technique (Rint)), the impulse 
Table 1. - Demographic data of the study population

\begin{tabular}{lcc}
\hline & Mean \pm SD & Range \\
\hline Subjects n & 110 & \\
Males/females & $67 / 43$ & \\
Age yrs & $3.75 \pm 0.96$ & $2.0-5.58$ \\
Height cm & $101.1 \pm 8.1$ & $84-120$ \\
Weight kg & $16.6 \pm 2.9$ & $11-24$ \\
\hline
\end{tabular}

oscillation technique (IOS), and a single-step method for measuring specific airway resistance (sRaw) by means of whole body plethysmography. The technical features of the equipment and measurement procedures have been described in detail previously $[2,3,5]$. All measurement procedures used in this study were identical to those employed in a recent study establishing reference values for lung function in young children [4].

The IOS parameters used were the resistance at $5 \mathrm{~Hz}$ $(R \mathrm{rs}, 5)$ and the reactance at $5 \mathrm{~Hz}(X \mathrm{rs}, 5)$, for which the coherence function was calculated. $s$ Raw was calculated from the specific resistance loops using the line connecting the maximum change in plethysmographic volume during inspiration and expiration [4]. Children who were unable to perform the plethysmographic procedures alone were accompanied by an adult [5].

\section{Procedures}

The measurements of lung function were performed after clinical evaluation of the children. The response to an inhaled bronchodilator was studied in a subset of children. Terbutaline 0.5 mg (Bricanyl; Astra, Copenhagen, Denmark) was inhaled from a low volume metal spacer (NebuChamber, Astra) and measurements of lung function were obtained $20 \mathrm{~min}$ later.

\section{Analysis of data}

The reproducibility of the measurements was estimated by means of the within subject SD (SDw), calculated as the SD of the differences between paired measurements from all subjects divided by $\sqrt{2}$. Measurements in individual patients were calculated as the mean of paired measurements. Lung function data were expressed as a percentage of the predicted value according to height [4]. Measurements were considered suggestive of impaired respiratory function if above the $97.5 \%$ prediction limit of the reference value (values below the $2.5 \%$ prediction limit for $X \mathrm{rs}, 5)$. The percentage of children with measurements outside the reference range was compared in children aged above and below the mean age of the study population (3.75 yrs). The difference between pre- and postbronchodilator measurements was expressed as a multiple of the SDW of the individual method. An unpaired t-test was used for comparing mean values of continuous variables. Differences in proportions were assessed using the Chi-squared test. The Mann-Whitney rank sum test for unmatched data was used for comparing data that were not normally distributed. A p-value $<0.05$ was considered statistically significant.

\section{Results}

\section{Study population}

One hundred and forty five children entered the study. Six children had clinical signs of airway obstruction and were excluded from the study. No measurements could be obtained in 29, children (mean age $2.9 \pm 0.54 \mathrm{yrs}$ ) of whom 21 were receiving regular treatment with inhaled steroids and eight were treated with inhaled $\beta_{2}$-agonists as required. Lung function measurements were obtained in 110 asymptomatic children. The demographic data of the children who completed measurements are given in table 1 . Thirty four per cent of the children had a history of eczema. Current or past asthma or hayfever requiring medical treatment was reported by either parent in $31 \%$ of children.

\section{Antiasthmatic treatment}

Seventy two $(65 \%)$ children were treated with inhaled steroids on a regular basis and had been on this treatment for $\geq 1$ month prior to testing of lung function; $38(35 \%)$ were treated only with inhaled $\beta_{2}$-agonists as required. Of the children treated with inhaled steroids, budesonide was used by $93 \%$, with a mean dose of $431 \mu \mathrm{g} \cdot \mathrm{day}^{-1}$ (range 100 $800 \mu \mathrm{g} \cdot$ day $^{-1}$ ). Most children were studied during the initial high-dose induction phase of this treatment [6]. The medication was administered by metered-dose inhaler with a plastic spacer device in all children except one who used a dry powder inhaler.

\section{Lung function measurements}

Lung function measurement data are given in table 2. The sDw of sRaw, Rint, $R \mathrm{rs}, 5$ and $X \mathrm{rs}, 5$ were $0.12,0.10,0.13$ and 0.11 respectively. Measurements suggestive of impaired respiratory function were found in 14, 44, 7.5 and $11 \%$ of the children for sRaw, Rint, $R \mathrm{rs}, 5$ and $X \mathrm{rs}, 5$, respectively (fig. 1). The coherence function of IOS measurements at $5 \mathrm{~Hz}$ was $0.71 \pm 0.11$. Measurements above the reference range were particularly prevalent among the youngest children. Rint were above the reference range in $59 \%$ of the children aged $2-3.75$ yrs in comparison with $29 \%$ in children aged $3.8-5.75$ yrs $(\mathrm{p}<0.05)$. The

Table 2. - Lung function data from 110 asymptomatic young asthmatic children

\begin{tabular}{lcccc}
\hline & $\begin{array}{c}\mathrm{s} R \mathrm{aw} \\
\mathrm{kPa} \cdot \mathrm{s}\end{array}$ & $\begin{array}{c}R \text { int } \\
\mathrm{kPa} \cdot \mathrm{L}^{-1} \cdot \mathrm{s}\end{array}$ & $\begin{array}{c}R \mathrm{rs}, 5 \\
\mathrm{kPa} \cdot \mathrm{L}^{-1} \cdot \mathrm{s}\end{array}$ & $\begin{array}{c}X \mathrm{rs}, 5 \\
\mathrm{kPa} \cdot \mathrm{L}^{-1} \cdot \mathrm{s}\end{array}$ \\
\hline Subjects $\mathrm{n}$ & 102 & 109 & 106 & 106 \\
Mean & $1.45 \pm 0.29$ & $1.35 \pm 0.31$ & $1.44 \pm 0.27$ & $-0.54 \pm 0.22$ \\
\% pred* & $109 \pm 22$ & $129 \pm 28$ & $104 \pm 20$ & $109 \pm 40$ \\
Subjects & $14^{\#}$ & $48^{\#}$ & $8^{\#}$ & $12^{+}$ \\
outside & & & & \\
normal & & & & \\
range n & & & & \\
\hline
\end{tabular}

Data are presented as mean \pm SD. *: values $>100 \%$ pred indicate reduced lung function; ${ }^{\#}$ : number of subjects with measurements $>97.5 \%$ limit of predicted normal value; ${ }^{+}$: number of subjects with measurements $<2.5 \%$ limit of predicted normal value. sRaw: specific airway resistance; Rint: resistance assessed using the interruptor technique; $R \mathrm{rs}, 5$ : respiratory resistance at $5 \mathrm{~Hz} ; X_{\mathrm{rs}, 5}$ : respiratory reactance at $5 \mathrm{~Hz}$. 
a)

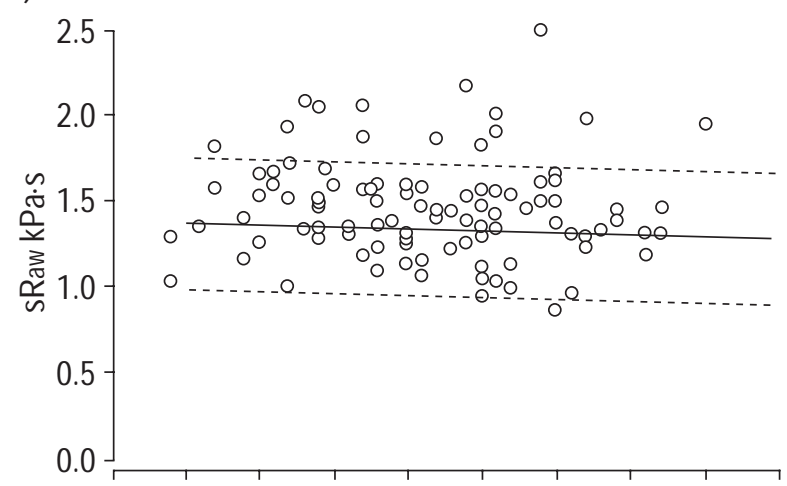

b)

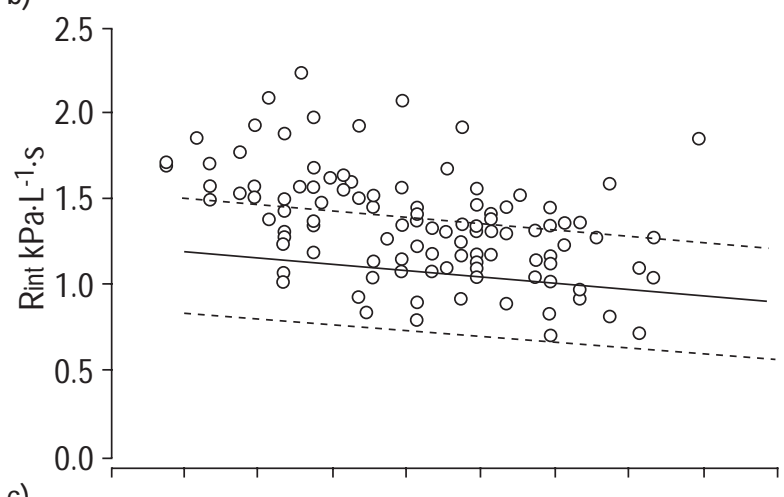

c)

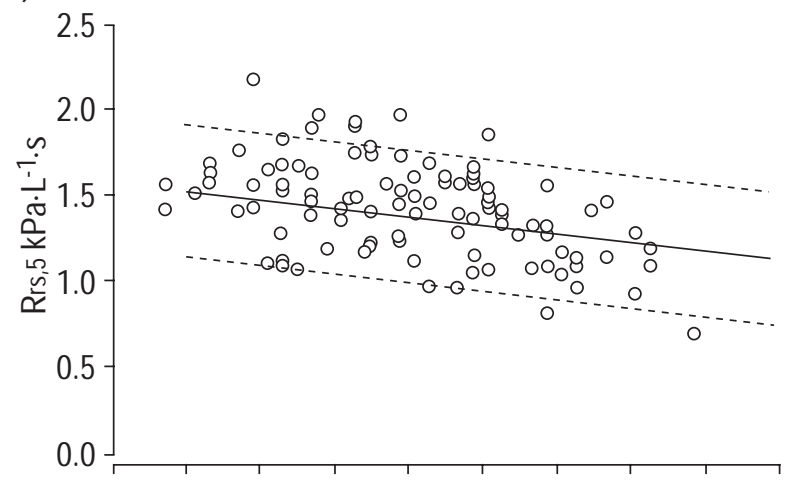

d)

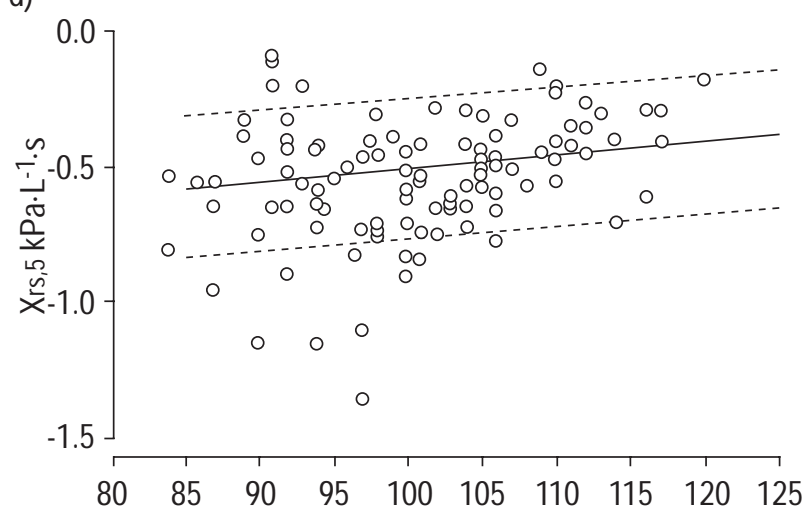

Fig. 1. - Lung function measurements in 109 asymptomatic young asthmatic children obtained by means of four different methods: a) specific airway resistance ( $\mathrm{s} R \mathrm{aw})$; b) resistance assessed using the interruptor technique $(R \mathrm{int})$; c) respiratory resistance at $5 \mathrm{~Hz}(R \mathrm{rs}, 5)$; and d) respiratory reactance at $5 \mathrm{~Hz}(X \mathrm{rs}, 5)$. - predicted normal value according to height; - - - - : 95\% limits of the predicted value. percentage of boys and girls with $R$ int above the reference range was not significantly different, 42 and $46 \%$, respectively. Measurements were completed with all of the applied methods in 95 children. Among these children the number of subjects with measurements suggestive of impaired lung function were 13, 41, eight and 11 children for sRaw, Rint, $R \mathrm{rs}, 5$ and $X \mathrm{rs}, 5$, respectively. Among the 41 children with $R$ int above the reference range, concordant findings with sRaw, $R \mathrm{rs}, 5$ and $X \mathrm{rs}, 5$ were found in seven, five and six children, respectively, and in two children only were the measurements above the reference range of all four methods.

The percentage of children in whom Rint were above the reference range was not significantly different between children treated with inhaled steroids (44\%) and children treated only with $\beta_{2}$-agonists as required (43\%). In 19 children with a history of eczema and at least one parent with asthma or rhinitis and in 50 children with no history of eczema and no parental asthma or rhinitis, the percentage of children with $R$ int above the reference range was not significantly different, 58 and $40 \%$, respectively.

\section{Bronchodilator response}

The response to inhalation of terbutaline was investigated in 31 children with an age of $3.9 \pm 0.9$ yrs. All indices of lung function changed significantly after bronchodilation. The change after bronchodilator was greatest for Rint, whereas $X \mathrm{rs}, 5$ showed the smallest change (table 3 ).

\section{Follow-up}

Follow-up data were obtained in 103 (94\%) (age $3.7 \pm 0.9 \mathrm{yrs})$ of the 110 children. Data were not available in seven children, who at the time of the initial lung function test had a mean age of 4.2 yrs. The observation period was $2.9 \pm 0.7$ yrs (range 1.6-3.9 yrs) and age of the children at follow-up $6.6 \pm 1.2 \mathrm{yrs}$. At follow-up, $84 \%$ of the children were no longer affiliated to the paediatric asthma outpatient department. Of the children, 58\% were still receiving antiasthmatic medication; $55 \%$ of males and $63 \%$ of females. Data on treatment at enrolment and at follow-up are given in table 4. The percentage of subjects receiving antiasthmatic medication at follow-up was nearly identical in children with $R$ int above and in children with $R$ int within the reference range at enrolment, $58 \%$ and $59 \%$, respectively. Of the children, $46 \%$ had current symptoms defined as one or more episodes of cough with wheeze lasting $>2$ days in the past year (table 4). In children with Rint above and in children with $R$ int within the reference range at enrolment, the percentage with current symptoms was not significantly different, $40 \%$ and $49 \%$, respectively.

Treatment with inhaled steroids had been withdrawn in $29(78 \%)$ of the 37 children who were younger than 4 yrs at enrolment, in comparison with $10(36 \%)$ of the 28 children aged $\geq 4$ yrs at enrolment $(\mathrm{p}<0.001)$. Among children currently treated with inhaled steroids, a significantly higher percentage $(54 \%)$ had suffered three or more episodes of cough with wheeze in the past year in comparison with $20 \%$ of children treated with $\beta_{2}$-agonist alone and $2 \%$ of children who received no treatment. At follow-up, 17 (89\%) of 19 children with a history of eczema and at least one parent 
Table 3. - Response to bronchodilator in asymptomatic children with recurrent wheeze

\begin{tabular}{|c|c|c|c|c|}
\hline & $\begin{array}{l}\mathrm{sRaw} \\
\mathrm{kPa} \cdot \mathrm{s}\end{array}$ & $\begin{array}{c}R \text { int } \\
\mathrm{kPa} \cdot \mathrm{L}^{-1} \cdot \mathrm{s}\end{array}$ & $\begin{array}{c}R \mathrm{rs}, 5 \\
\mathrm{kPa} \cdot \mathrm{L}^{-1} \cdot \mathrm{s}\end{array}$ & $\begin{array}{c}X \mathrm{rs}, 5 \\
\mathrm{kPa} \cdot \mathrm{L}^{-1} \cdot \mathrm{s}\end{array}$ \\
\hline Subje & & 31 & 31 & 3 \\
\hline \multicolumn{5}{|c|}{ Before bronchodilator } \\
\hline Mean & $1.47 \pm 0.28$ & 21 & $.48=$ & $-0.59 \pm$ \\
\hline$\%$ pred & $110 \pm 21$ & $128 \pm$ & 107 & \\
\hline \multicolumn{5}{|c|}{ After bronchodilator* } \\
\hline Mean & $133 \pm 0.31$ & 1.0 & 1.25 & -0.43 \\
\hline \% pre & $91 \pm$ & $103 \pm$ & $90 \pm 1$ & $85 \pm 2$ \\
\hline \multicolumn{5}{|l|}{ Difference $^{+}$} \\
\hline $\begin{array}{l}\Delta \text { SDW } \\
(95 \% \text { CI })\end{array}$ & $\begin{array}{c}2.1 \\
(1.4-2.9)\end{array}$ & $\begin{array}{c}2.7 \\
(2.0-3.3)\end{array}$ & $\begin{array}{c}2.1 \\
(1.3-2.9)\end{array}$ & $\begin{array}{c}1.5 \\
(1.0-2.0)\end{array}$ \\
\hline
\end{tabular}

Data are presented as mean $\pm \mathrm{SD}$. *: terbutaline $0.5 \mathrm{mg}$ inhaled from a low-volume metal spacer; ${ }^{+}$: between pre- and postbronchodilator measurements expressed as a multiple of the within subject SD (SDw). sRaw: specific airway resistance; Rint: resistance assessed using the interruptor technique; $R \mathrm{rs}, 5$ : respiratory resistance at $5 \mathrm{~Hz} ; X \mathrm{rs}, 5:$ respiratory reactance at 5 Hz.

with asthma or rhinitis were still on antiasthmatic treatment in comparison with $22(39 \%)$ of 51 children with no history of eczema and no parental asthma or rhinitis $(p<0.05)$, and the percentage of children who had suffered three or more episodes of cough with wheeze in the past year in the two groups was $47 \%$ and $14 \%$, respectively $(\mathrm{p}<0.05)$

\section{Discussion}

In this study, subclinical impairment of lung function was found in a considerable proportion of stable young asthmatic children considered to be appropriately treated. After a mean follow-up period of 3 yrs, the outcome was similar, in terms of treatment and symptoms, in children who had impairment of lung function and in children who had normal lung function at enrolment in the study. Hence, lung function measurements were not helpful in identifying children with a poor prognosis.

\section{Lung function measurements}

The present results show that the sensitivity of clinical assessment of respiratory function in young children is poor. Lung function measurements are therefore likely to be a useful tool in the early identification of young children with significant though not clinically apparent impairment of lung function, and as a means of objective assessment of the response to medical treatment. Rint identified impair- ment of lung function in more children than did $\mathrm{s}$ Raw and IOS measurements, although the sensitivity of the methods to changes after bronchodilation was almost the same. The fact that the methods reflect different mechanical properties of the respiratory system is probably the most important factor in explaining the poor agreement between the methods. The reference values employed in this study were collected in healthy children concurrently with the measurements in asthmatic children. Therefore, it is unlikely that the present findings could be caused by a systematic error.

The majority of the children in the present cohort (65\%) were treated with inhaled steroids likely to have improved lung function [7-10]. The high prevalence of lung function impairment despite treatment may be due to airway inflammation or sequelae thereof, although some children may have congenital diminishment of airway function [11-14].

\section{Follow-up}

The children included in this study were referred from general practitioners and the vast majority of the children had mild or moderate symptoms. They were initially treated according to the treatment strategy currently employed in Denmark, using inhaled steroids as first-line therapy not only in children with severe or persistent symptoms but also in children who have recurrent mild wheezing apart from respiratory tract infections. Inhaled steroids are initially given in high doses and subsequently tapered of, and, in the absence of symptoms, treatment is stopped to ascertain the need for continuous treatment $[6,15]$. Cromoglycates are not used and treatment with $\beta_{2}$-agonists as needed as monotherapy is confined to children with infrequent mild symptoms.

The outcome after a mean period of time of almost $3 \mathrm{yrs}$ was assessed using the requirement for antiasthmatic therapy and symptoms during the past year as outcome measures. The requirement for antiasthmatic therapy and symptoms at follow-up were not different between children with impairment of lung function at enrolment in the study and children who had normal lung function. However, at the time of follow-up, the majority of the children were treated by their general practitioner and therefore probably not treated uniformly according to the guidelines. Furthermore, the number of episodes of cough with wheeze in the children as reported by their parents provided only a crude estimate of the presence and severity of asthmatic symptoms [16]. This may restrict, but not invalidate, the present assessment of outcome, which supported by the fact that that, in keeping with findings

Table 4. - Relation between antiasthmatic inhalation therapy at enrolment and therapy and asthmatic symptoms at followup in 103 children

\begin{tabular}{|c|c|c|c|c|}
\hline \multirow{2}{*}{ Therapy at follow-up } & \multicolumn{2}{|c|}{ Therapy at enrolment } & \multicolumn{2}{|c|}{ Asthmatic symptoms at follow-up* } \\
\hline & Steroid n (\%) & $\beta_{2}$-agonist n (\%) & No current symptoms $\mathrm{n}$ & $\begin{array}{l}\text { Current symptoms } \mathrm{n} \\
\text { (median, range) }\end{array}$ \\
\hline Steroid & $26(40)$ & $9(24)$ & 5 & $30(3.5,1-10)$ \\
\hline$\beta_{2}$-agonist & $16(25)$ & $9(24)$ & 16 & $9(3.0,1-4)$ \\
\hline No medication & $23(35)$ & $20(52)$ & 35 & $8(1.5,1-4)$ \\
\hline
\end{tabular}

*: one or more episodes of cough with wheeze lasting $>2$ days during the past year. 
in other studies [13, 17-19], among children with an atopic predisposition a significantly higher percentage was found that had current symptoms and were currently on anti-asthmatic therapy in comparison with children without an atopic predisposition. Treatment with inhaled steroids had been withdrawn in $78 \%$ of the children who were younger than 4 yrs at enrolment in comparison with $36 \%$ of children aged $\geq 4$ yrs at enrolment, indicating that 2-3 yrs-old children with asthmatic symptoms have a more favourable prognosis than 4-5 yr-olds with asthmatic symptoms.

To the authors' knowledge this is the first report on lung function status in a large group of young children with asthmatic symptoms after the second year of life treated according to current guidelines. In this group of clinically stable asthmatic children, it was found that impairment of lung function was common in $2-5$ yr-olds, but not associated with an unfavourable outcome as judged by symptoms and requirement for treatment 3 yrs later. The clinical implications of demonstrating airway obstruction by means of lung function measurement in young asthmatic children deserves further study.

\footnotetext{
Acknowledgements. The authors thank $\mathrm{T}$ Bengtsson for the statistical analysis.
}

\section{References}

1. Warner JO, Gotz M, Landau LI, et al. Management of asthma: a consensus statement. Arch Dis Child 1989; 64: 1065-1079.

2. Bisgaard H, Klug B. Lung function measurement in awake young children. Eur Respir J 1995; 8: 2067-2075.

3. Klug B, Bisgaard $\mathrm{H}$. Measurement of lung function in awake 2-4-yr-old asthmatic children during methacholine challenge and acute asthma: a comparison of the impulse oscillation technique, the interruptor technique, and transcutaneous measurement of oxygen versus wholebody plethysmography. Pediatr Pulmonol 1996; 21: 290300.

4. Klug B, Bisgaard H. Specific airway resistance, interruptor resistance, and respiratory impedance in healthy children aged 2-7 yrs. Pediatr Pulmonol 1998; 25: 322331.

5. Klug B, Bisgaard H. Measurement of the specific airway resistance by plethysmography in young children accompanied by an adult. Eur Respir J 1997; 10: 1599-1605.
6. Bisgaard H. Use of inhaled corticosteroids, in pediatric asthma. Pediatr Pulmonol Suppl 1997; 15: 27-33.

7. Martinez FD, Morgan WJ, Wright AL, Holberg C, Taussig LM. Initial airway function is a risk factor for recurrent wheezing respiratory illnesses during the first three years of life. Group Health Medical Associates. Am Rev Respir Dis 1991; 143: 312-316.

8. Young S, Arnott J, Le Souef PN, Landau LI. Flow limitation during tidal expiration in symptom-free infants and the subsequent development of asthma. $J$ Pediatr 1994; 124: 681-688.

9. Martinez FD, Wright AL, Taussig LM, Holberg CJ, Halonen M, Morgan WJ. Asthma and wheezing in the first six years of life. The Group Health Medical Associates. $N$ Engl J Med 1995; 332: 133-138.

10. Rye PJ, Palmer LJ, Young S, et al. The association between infant lung function and respiratory symptoms during the first 6 years of life. Am J Respir Crit Care Med 1995; 151: A468.

11. Gleeson JG, Price JF. Controlled trial of budesonide given by the nebuhaler in preschool children with asthma. $B M J$ 1988; 297: 163-166.

12. Wennergren G, Nordvall SL, Hedlin G, Moller C, Wille S, Asbrink Nilsson E. Nebulized budesonide for the treatment of moderate to severe asthma in infants and toddlers. Acta Paediatr 1996; 85: 183-189.

13. Connett GJ, Warde C, Wooler E, Lenney W. Use of budesonide in severe asthmatics aged 1-3 years. Arch Dis Child 1993; 69: 351-355.

14. Bisgaard H, Munck SL, Nielsen JP, Petersen W, Ohlsson SV. Inhaled budesonide for treatment of recurrent wheezing in early childhood. Lancet 1990; 336: 649-651.

15. The General Practitioner in Asthma Group, the British Association of Accident and Emergency Medicine, the British Paediatric Respiratory Society and the Royal College of Paediatrics and Child Health. Asthma in children under five years of age. Thorax 1997; 52: S9-S10.

16. Wilson N, van Bever H. Overall symptom measurement: which approach? Eur Respir J Suppl 1996; 21: 8s-11s.

17. Brooke AM, Lambert PC, Burton PR, Clarke C, Luyt DK, Simpson H. The natural history of respiratory symptoms in preschool children. Am J Respir Crit Care Med 1995; 152: $1872-1878$.

18. Wennergren G, Hansson S, Engstrom I, et al. Characteristics and prognosis of hospital-treated obstructive bronchitis in children aged less than two years. Acta Paediatr 1992; 81: 40-45.

19. Foucard T, Sjoberg O. A prospective 12-year follow-up study of children with wheezy bronchitis. Acta Paediatr Scand 1984; 73: 577-583. 